\title{
BRAKE SYSTEM PERFORMANCE EVALUATION OF FORMULA TYPE VEHICLE
}

\author{
Felipe Mestre ${ }^{1}$, Kaue B. Pironato ${ }^{1}$, Romulo M. Silva ${ }^{1}$, Paulo Lee ${ }^{1}$, Sergio K. Moriguchi ${ }^{1}$, \\ Fernando Malvezzi ${ }^{1}$ \\ ${ }^{1}$ Maua Institute of Technology \\ E-mails: author 5: moriguchi@maua.br, author 6: fernando.malvezzi@maua.br
}

\begin{abstract}
Formula Student and Formula SAE are student competitions where engineering students must develop a Formula type vehicle according to a series of rules. Regarding to the brake system, these rules determine some requirements that the cars must be in accordance.

This work deals with a performance evaluation of brake system of Formula type vehicle. First, a mathematical model was developed to achieve the balance of front and rear braking forces. This model takes into account the most important vehicle parameters that influence braking performance, as well as the tire/road friction conditions. Then, the results obtained from the model were compared against experimental data. During the tests the vehicle velocity, the lateral and longitudinal vehicle acceleration and the circuit pressure to the front and rear brakes were monitored. This mathematical model will be employed to development of brake systems to be applied to Formula type vehicle.

Finally, a second experimental test was employed to evaluate the brake system performance considering the vehicle operating in competition conditions.

The obtained results show that the mathematical model is suitable for brake system performance prediction. Moreover, the tests results show that the brake system is suitable under competition conditions.
\end{abstract}

\section{INTRODUCTION}

The Formula SAE is a student competition organized by SAE International in which engineering students design and built a Formula type vehicle which is evaluated by a variety of static and dynamic events.

Regarding to the brake system, the Formula Student rules is similar to the SAE ones. These rules determine that the cars must be equipped with a braking system operated by a single control that acts on all four wheels. This system must have two independent hydraulic circuits such that in the case of failure at any point in the system, effective braking power is maintained on at least two wheels. The brake system must be capable to lock all four wheels during the specific test. "Brake-by-wire" systems are prohibited. The brake pedal must be designed to resist a force of $2000 \mathrm{~N}$ without any failure of the brake system or pedal box $[1,2]$.

The braking system is important not only for the safety but also for performance of racing cars [3]. An efficient brake system should achieve the maximum longitudinal force available in tire-pavement contact. 
According to Canale [4], the longitudinal force is caused by the tire deformation. The compressed fibers of tire expand so there is a relative slipping over the ground surface that creates the longitudinal force. The maximum value of this force in passenger vehicle tires is achieved when relative slip reaches the range from $10 \%$ to $20 \%$.

According to Gillespie, adhesion and hysteresis are the primary mechanisms for friction coupling [5]. These mechanisms depend on small amount of slip that occurs at the tirepavement contact.

In order to define the braking systems parameters, models for brake balance analysis have been employed. Limpert presented a vehicle braking dynamic model in which both aerodynamic and driveline drags are neglected [6]. Breuer and Bill show a braking dynamic model specific for race car in which the aerodynamic effects are taken into account but the engine torque during the braking maneuver is not considered [7].

Some works have presented Formula SAE braking development. Heffernan introduced an analytical technique for performing brake rotor temperature analysis using empirical data [8]. It can be useful to predict fading problems when the design disc brake system is developed.

Schommer et al. have applied a combination of topology optimization and Direct Metal Laser Sintering to manufacture of a FSAE brake caliper [9]. The results based on the thermal simulations showed that the new caliper achieved heat transfer improvements, and maintained a considerable stiffness.

This paper presents a brake system performance evaluation of Formula SAE type vehicle. A mathematical model was developed to know the balance of front and rear braking forces. In addition, an experimental test was employed to evaluate the brake system performance considering the vehicle operating in competition conditions.

\section{BRAKE SYSTEM}

The brake system of this work has got a disc brake in all of four wheels, with hydraulic drive and without assistance. The brake pedal activates two independent master cylinders, one to act on the front wheels and the other one to act on the rear wheels (Fig. 1-a).

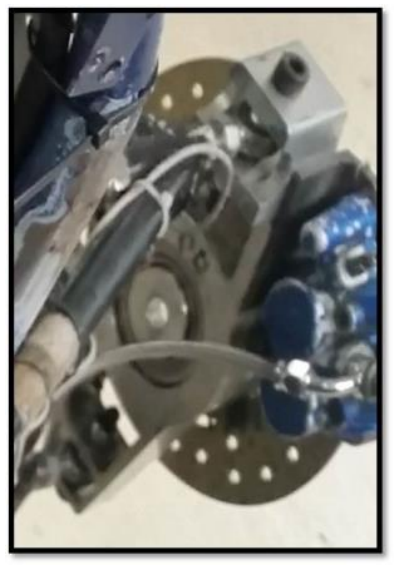

(a)

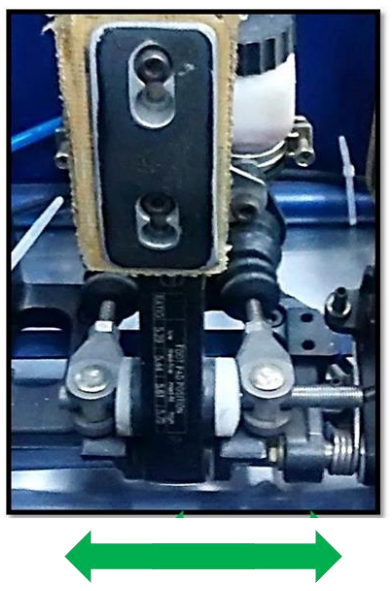

(b)

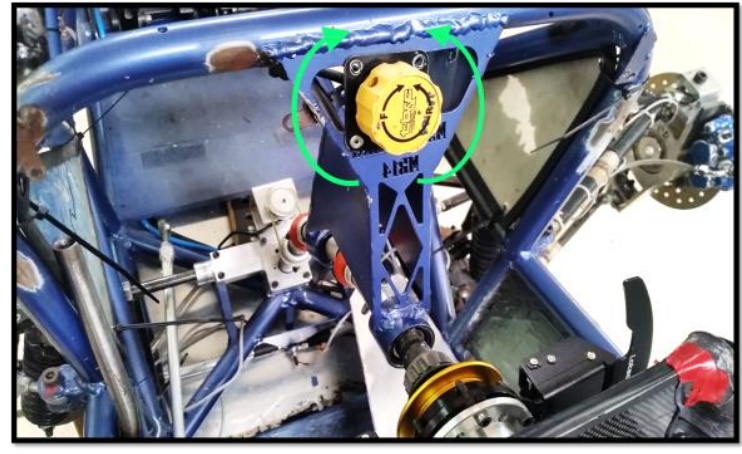

(c)

Figure 1. (a) Disc brake and caliper; (b) Brake bias; (c) Dial 
A brake bias system is used to control force distribution generated by the pedal between the two master cylinders (Fig. 1-b). The driver can adjust the brake balance via a dial located in the cockpit (Fig. 1-c).

Therefore, the balancing of the braking forces between the front and rear axles is achieved by the pressure difference between the front and rear circuits. The brake bias system allows using the same wheel cylinders and the same disc brakes on both axles, reducing the number of components types.

\section{MODELING AND BRAKE BALANCE ANALYSIS}

The forces responsible to generate vehicle deceleration are originated not only by the braking forces but also by the tire rolling resistance, aerodynamic drag, driveline inertia effects and driveline drag.

Only the forces generated by the brake system are considered in the analysis developed in this work. The approach presented here is based on Limpert work [6]. This analysis considers both the optimum braking forces and the actual braking forces.

The vehicle parameters employed in this work are presented in the Appendix.

\subsection{Optimum Braking Force}

The optimum braking force distribution is achieved when all wheels reach the imminent locking simultaneously $[5,6,10]$. The model developed to calculate these forces take into account the following hypothesis: both the tire rolling resistance and the aerodynamic drag are neglected; the braking occurs only in straight line and with uncoupled transmission; the tires are on the imminence of locking during braking and the wheel moment of inertia is negligible. Although the vehicle analyzed in this work is a single seater race car, it is not equipped with wings and during competitions the velocity usually is lower than $75 \mathrm{~km} / \mathrm{h}$.

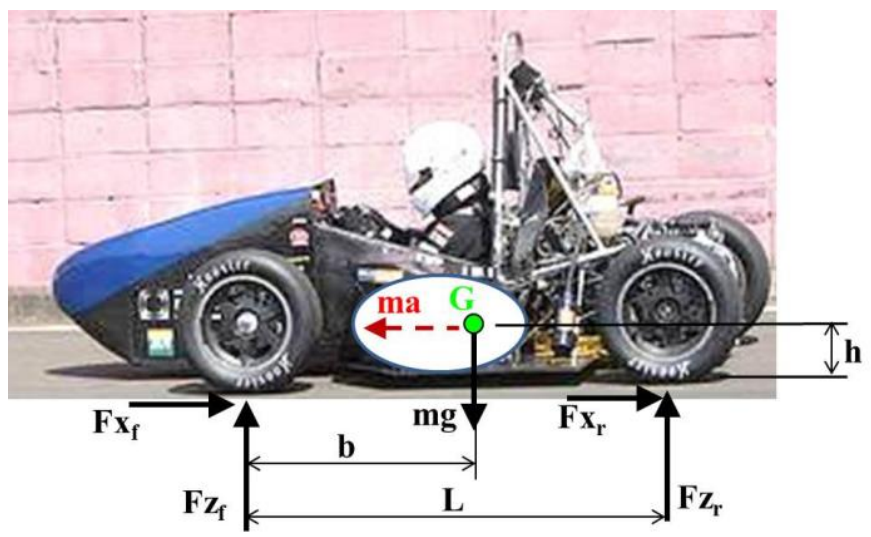

Figure 2. Forces acting on vehicle during braking

Appling the Newton-Euler equations for the system of Fig. 2 one obtains:

$$
\begin{aligned}
& F z_{f}=m g\left(1-\frac{b}{L}\right)+\frac{m a h}{L} \\
& F z_{r}=m g\left(\frac{b}{L}\right)-\frac{m a h}{L}
\end{aligned}
$$




$$
a=g \mu
$$

Where:

$F z_{f}$ : front axle vertical load

$F z_{r}$ : rear axle vertical load

$m$ : vehicle mass (driver included)

$g:$ gravitational acceleration

$b$ : distance between front axle and gravitational center

$L$ : wheel base length

$h$ : gravitational center height

$a$ : longitudinal deceleration

$\mu$ : tire/road adhesion coefficient

The optimum front and rear braking forces are obtained by applying equations (4) and (5), respectively:

$$
\begin{aligned}
& F x_{f}=F z_{f} \mu \\
& F x_{r}=F z_{r} \mu
\end{aligned}
$$

Where:

$F x_{f}:$ front axle braking force

$F x_{f}$ : rear axle braking force

The forces $F x_{f}$ and $F x_{r}$ can be expressed relative to vehicle weight by dividing the braking forces $F x_{f}$ and $F x_{r}$ by vehicle weight. Moreover, substituting equation (3) in equations (1) and (2) we obtain:

$$
\begin{aligned}
& \frac{F x_{f}}{m g}=\left(1-\frac{b}{L}\right) \mu+\frac{h}{L} \mu^{2} \\
& \frac{F x_{r}}{m g}=\frac{b}{L} \mu-\frac{h}{L} \mu^{2}
\end{aligned}
$$

Adopting values between 0 and 1.4 for the tire/road adhesion coefficient equations (6) and (7) lead to the graph showed in Fig. 3. As different drivers can drive the car during competition, Fig. 3 presents two optimum curves for two different vehicle gravitational center positions. 


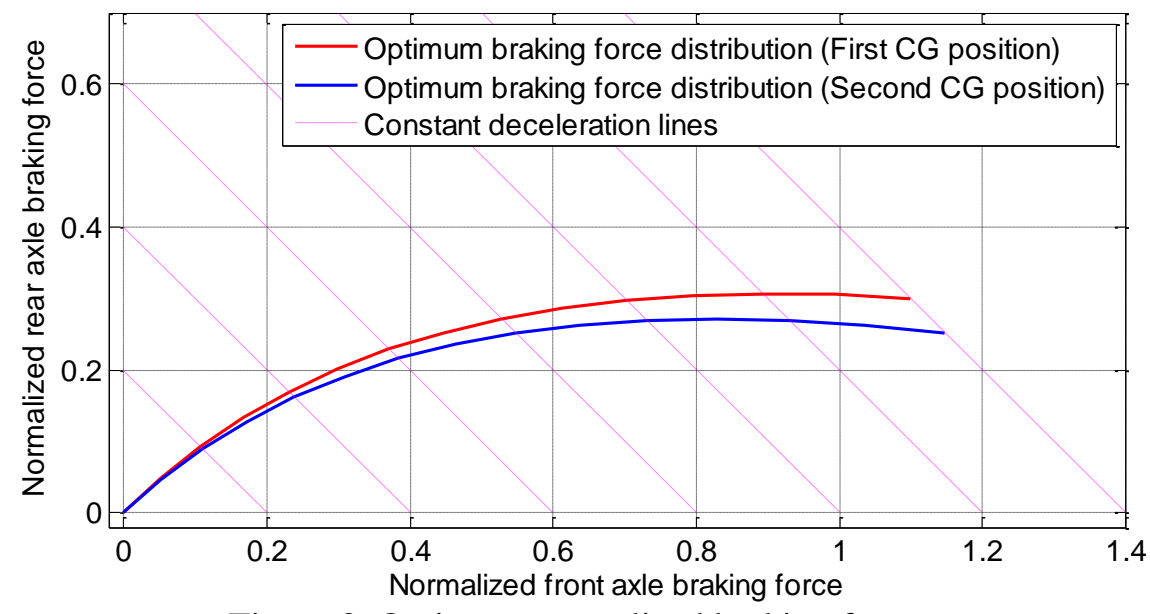

Figure 3. Optimum normalized braking forces

\subsection{Actual Braking Force}

The actual braking force modelling was developed to determine the front and rear axle braking force. These real forces were compared to the optimum braking forces to evaluate the installed braking system efficiency.

The brake pedal force is distributed between the front and rear master cylinders through a device called brake bias (brake balance), which allows the driver to control the distribution of braking forces between the front and rear axles in order to maximize overall brake balance during competition.

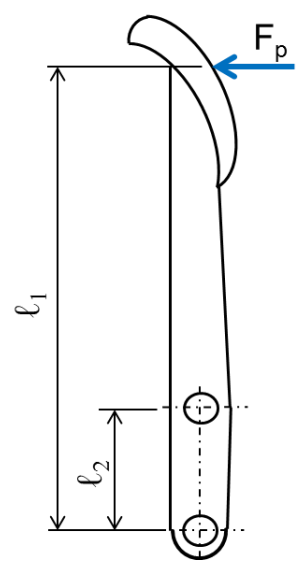

Figure 4. Brake pedal dimensions

The pressures generated by the front and rear master cylinders are determined by the equations (8) and (9), respectively.

$$
\begin{aligned}
& p_{f}=\frac{F_{p}}{A_{M f}} i_{p} \beta \\
& p_{r}=\frac{F_{p}}{A_{M r}} i_{p}(1-\beta)
\end{aligned}
$$


Where:

$p_{f}$ : front brake circuit pressure

$p_{r}$ : rear brake circuit pressure

$F_{p}:$ pedal force

$A_{M f}$ : effective area of front master cylinder

$A_{M r}$ : effective area of rear master cylinder

$i_{p}:$ pedal ratio $\left(\ell_{1} / \ell_{2}\right)$

$\ell_{1}$ : distance from foot to pedal pivot (Fig. 4)

$\ell_{2}$ : distance from pushrod to pedal pivot (Fig. 4)

$\beta$ : brake bias ratio (front-to-rear)

The brake system of this work is floating caliper disc brake. At this system, the torque applied to the disc brake is obtained by equation (10).

$$
T_{\text {disc }}=2 \cdot p \cdot A_{c} \cdot \mu_{p a d} \cdot R_{c}
$$

Where:

$T_{\text {disc }}:$ torque applied to each disc brake

$\mu_{\text {pad }}: \mathrm{pad} / \mathrm{disc}$ brake coefficient of friction

$R_{c}$ : effective radius disc brake

$p$ : brake circuit pressure

$A_{c}:$ caliper piston area

Neglecting the inertia moment of wheels, the front axle braking force at straight-line braking, expressed in reference to vehicle weight is:

$$
\frac{F x_{f}}{m g}=\frac{2 \cdot\left(p_{f}-p_{0}\right) \cdot A_{c f} \cdot R_{c f} \cdot C^{*}}{R_{t} \cdot m \cdot g} \eta
$$

In the same conditions, the rear axle braking force expressed in reference to vehicle weight is:

$$
\frac{F x_{r}}{m g}=\frac{2 \cdot\left(p_{r}-p_{0}\right) \cdot A_{c r^{*}} R_{c r^{*}} C^{*}}{R_{t} \cdot m \cdot g} \eta
$$

Where:

$p_{0}$ : pushout pressure 
$C^{*}$ : brake factor $\left(2 \mu_{p a d}\right)$

$R_{t}$ : tire rolling radius

$\eta$ : wheel cylinder efficiency

$A_{c f}$ : front caliper piston area

$A_{c r}$ : rear caliper piston area

$R_{c f}$ : front disc effective radius

$R_{c r}$ : rear disc effective radius

Considering a pedal force of $425 \mathrm{~N}$, a brake bias ratio equal to $71.5 \%$ and applying Eq. (8), (9), (11) and (12), one obtains the actual braking force distribution, as shown in Fig. 5. The optimum braking force curve intersects the actual braking force line when the vehicle achieves a deceleration equal to $1.0 \mathrm{~g}$. If the maximum tire/road adhesion coefficient is achieved when the vehicle deceleration is equal to $1.0 \mathrm{~g}$, there will be a simultaneous locking of the four wheels. When decelerations are higher than $1.0 \mathrm{~g}$, the locking of rear axle will occur first. On the other hand, when decelerations are lower than $1.0 \mathrm{~g}$, the locking of front axle will occur first.

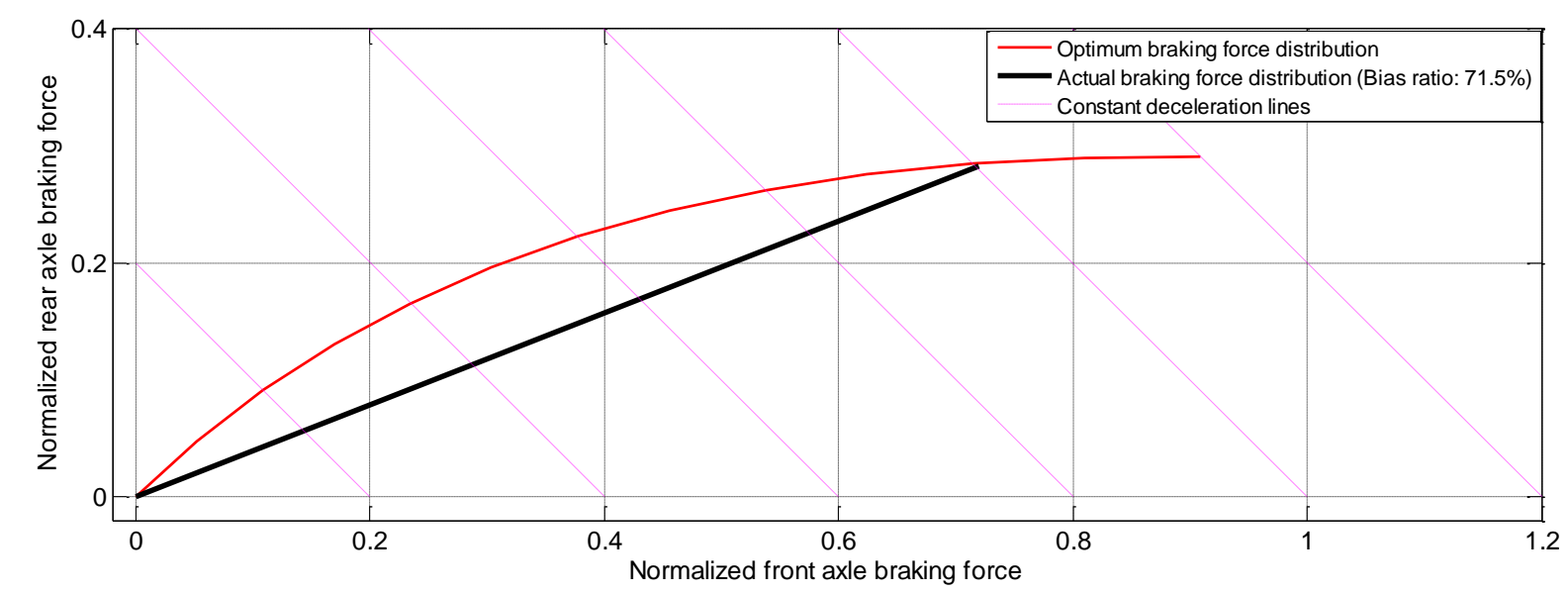

Figure 5. Actual and optimum braking force distribution (driver mass of $78 \mathrm{~kg}$ )

Figure 6 represents the optimum and the actual braking force distribution referred to the operating range of the brake bias. This range is sufficient for the drivers to achieve the optimum brake balance during competition. 


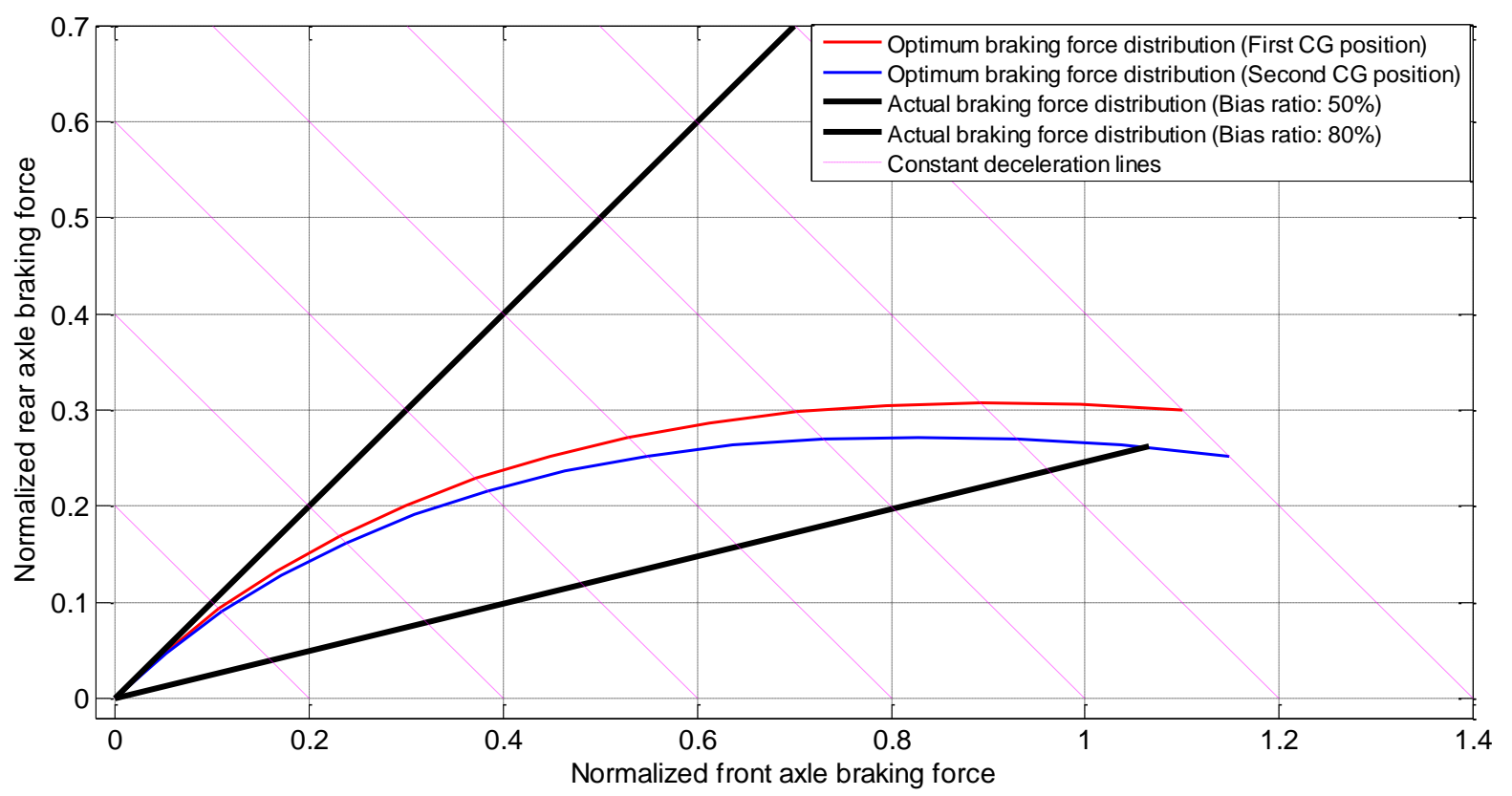

Figure 6. Normalized optimum and actual braking force distribution

\subsection{Pedal Force Gain}

In order to evaluate the pedal force during braking, the pedal force gain was calculated, which is the relation between pedal force and vehicle deceleration [5]. According to the model prediction, the required pedal force to the vehicle achieves a deceleration of $1.0 \mathrm{~g}$ is $425 \mathrm{~N}$, considering a mass of the driver equal to $78 \mathrm{~kg}$. For a driver mass of $60 \mathrm{~kg}$, this force is $404 \mathrm{~N}$ and for $90 \mathrm{~kg}$ the force is $438 \mathrm{~N}$. These values were compared to NHTSA research, which has identified an optimum range for pedal force gain, as seen in Fig. 7. As there is no specific reference for formula cars type, a NHTSA recommendation developed for passenger was used for the single seater race car of this study. The red points in Fig. 7 represent the pedal force gain for the three drivers.

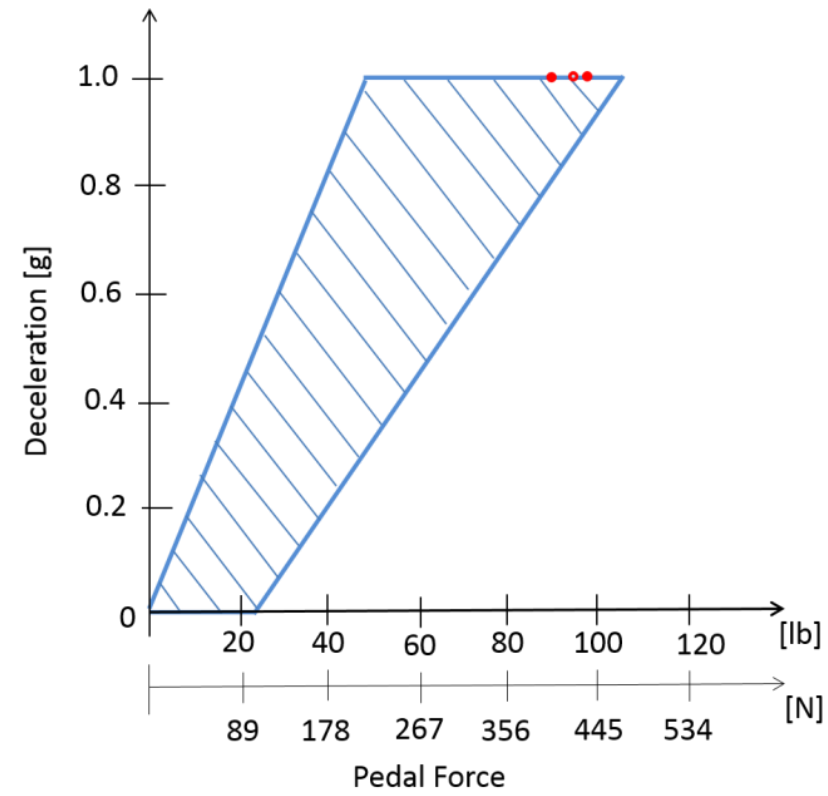

Figure 7. Pedal Force Gain - according to NHTSA shaded area represents the optimum gain 


\section{TESTS PROCEDURE}

Two tests were performed to evaluate the brake system. In the first one, the results obtained with the mathematical model were compared to collected data during experimental tests to evaluate this model. The second test analyzed the performance of the braking system in a competition circuit. Both tests were monitored by sensors to measure the pressure on the front and rear lines of the brake system, the longitudinal and lateral acceleration and the velocity of the vehicle.

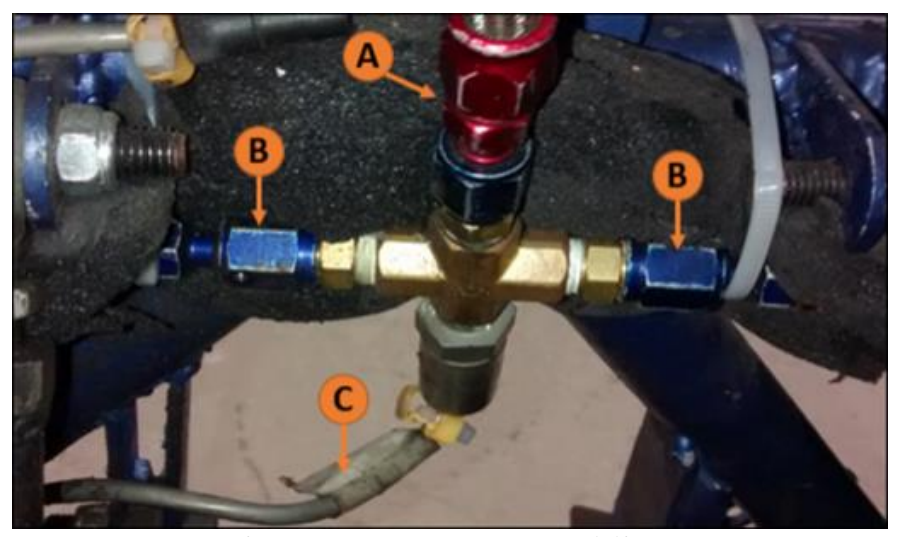

Figure 8. Sensors assembling

Figure 8 presents the connection of the inlet (A) with the outlet for each wheel cylinder (B) and the pressure sensor $(\mathrm{C})$. When the brake pedal is pressed, the system is pressurized by the brake fluid and the sensor performs the pressure reading, sending the data to the $\mathrm{AIM}^{\circledR}$ data acquisition system.

The longitudinal and lateral vehicle accelerations were obtained via an accelerometer assembled near to the center of gravity of the vehicle.

The track and velocity of the vehicle were obtained via GPS-Global Position System. In addition, the GPS was employed to identify the braking points presented in Figure 9.

The setting of brake bias employed during the tests was determined by equation (13).

$$
\beta=\frac{P_{f}}{P_{f}+P_{r}}
$$

\subsection{Comparison of model and track test results}

The test to evaluate the model accuracy was performed on a flat and dry asphalt racetrack. This test procedure was based on accelerated the vehicle up to the reference speed of $60 \mathrm{~km} / \mathrm{h}$. After that, the car was braked in straight-line and without motor action (acting on the brake pedal and clutch simultaneously) until it stopped completely. Right after the car stopped completely, the temperatures of the four brake pads were measured.

Tests were performed at different positions of brake bias. In all of the tests, the driver applied a "soft" force on the brake pedal. Then, these procedures were repeated with a "strong" intensity braking. Table 1 shows the vehicle parameters and weather conditions during model evaluation test. 
Table1. Vehicle parameters and weather conditions during model validation test

\begin{tabular}{cc}
\hline Vehicle parameters/ & Values \\
weather conditions & \\
\hline Asphalt temperature & Between $26^{\circ} \mathrm{C}$ and $40{ }^{\circ} \mathrm{C}$ \\
Initial temperature of tires & $23^{\circ} \mathrm{C}$ \\
Initial temperature of pads & $25^{\circ} \mathrm{C}$ \\
Air temperature & $28^{\circ} \mathrm{C}$ \\
Tire inflation pressure (cold tire) & $13 \mathrm{psi}(90 \mathrm{kPa})$ \\
Camber (front and rear wheels) & $0^{\circ}$ \\
Toe (front and rear wheels) & $0^{\circ}$ \\
\hline
\end{tabular}

\subsection{Performance test of brake system at a competition circuit}

Performance tests were conducted on the ECPA (a private racing circuit in Sao Paulo-Brazil), in dry asphalt racetrack. As the tests evaluated the performance of the brake system in race conditions, the driver did not activate the clutch during braking. Moreover, the driver actuated on the brake pedal in turns, which influenced the maximum tire longitudinal force due to the lateral acceleration effects [11].

Table 2 shows the vehicle parameters and weather conditions during competition circuit test.

Table 2. Vehicle parameters and weather conditions during competition circuit test

\begin{tabular}{cc}
\hline Vehicle parameters/ & Values \\
weather conditions & \\
\hline Asphalt temperature & Between $28^{\circ} \mathrm{C}$ and $40{ }^{\circ} \mathrm{C}$ \\
Initial temperature of tires & $24^{\circ} \mathrm{C}$ \\
Initial temperature of pads & $26^{\circ} \mathrm{C}$ \\
Air temperature & $32^{\circ} \mathrm{C}$ \\
Tire inflation pressure (cold tire) & $13 \mathrm{psi}(90 \mathrm{kPa})$ \\
Front wheels camber & $-2^{\circ}$ \\
Rear wheels camber & $0^{\circ}$ \\
Toe (front and rear wheels) & $0^{\circ}$ \\
\hline
\end{tabular}

\section{TESTS RESULTS}

\subsection{Results obtained from model evaluation test}

In the mathematical model evaluation test, two longitudinal accelerations were compared: one from the vehicle braking and the other one obtained from the model.

As it was not possible to determine the force applied on the pedal by the driver during the test (in real time), the measured pressure values obtained by the test were used into the equations (11) and (12). Then, the vehicle deceleration was calculated by summing the values calculated from equations (11) and (12).

Table 3 shows front and rear pressure circuits and longitudinal vehicle deceleration obtained during tests. The graphs with all collected data are presented in the Appendix. In addition, 
Table 3 shows a comparison between the values of deceleration obtained from the model and the values measured during the tests. The experimental data collected during the tests were disregarded when the lateral accelerations were higher than $0.10 \mathrm{~g}$, the longitudinal decelerations were lower than $0.35 \mathrm{~g}$ or higher than $1,50 \mathrm{~g}$.

Table 3. Pressure lines and longitudinal vehicle deceleration

\begin{tabular}{cccccc}
\hline Test & $\begin{array}{c}\text { Front Line } \\
\text { Pressure } \\
(\mathrm{MPa})\end{array}$ & $\begin{array}{c}\text { Rear Line } \\
\text { Pressure }(\mathrm{MPa})\end{array}$ & $\begin{array}{c}\text { Actual } \\
\text { deceleration } \\
(\mathrm{g})\end{array}$ & $\begin{array}{c}\text { Model } \\
\text { deceleration } \\
(\mathrm{g})\end{array}$ & $\begin{array}{c}\text { Error } \\
(\%)\end{array}$ \\
\hline 1 & 5.54 & 4.44 & 1.03 & 1.16 & 12.60 \\
2 & 7.92 & 5.62 & 1.48 & 1.57 & 6.08 \\
3 & 4.38 & 3.00 & 0.95 & 0.86 & 9.47 \\
4 & 3.12 & 1.86 & 0.58 & 0.58 & 0 \\
5 & 3.13 & 1.61 & 0.62 & 0.55 & 11.29 \\
6 & 2.08 & 1.00 & 0.38 & 0.36 & 5.26 \\
\hline
\end{tabular}

The disc brake temperature was monitored and measured at the end of braking. Table 4 shows the temperature of disc brake immediately after the braking.

Table 4. Disc brake temperature $\left({ }^{\circ} \mathrm{C}\right)$

\begin{tabular}{cccccc}
\hline Test & $\begin{array}{c}\text { Right } \\
\text { Front }\end{array}$ & $\begin{array}{c}\text { Left } \\
\text { Front }\end{array}$ & $\begin{array}{c}\text { Right } \\
\text { Rear }\end{array}$ & $\begin{array}{c}\text { Left } \\
\text { Rear }\end{array}$ & $\begin{array}{c}\text { Brake Bias } \\
(\%)\end{array}$ \\
\hline 1 & 131 & 135 & 123 & 126 & 55.5 \\
2 & 142 & 157 & 103 & 113 & 58.5 \\
3 & 86 & 93 & 72 & 70 & 59.3 \\
4 & 74 & 77 & 65 & 72 & 62.6 \\
5 & 130 & 124 & 91 & 97 & 66.0 \\
6 & 88 & 91 & 79 & 73 & 67.5 \\
\hline
\end{tabular}

The maximum temperature reached during the test was $157^{\circ} \mathrm{C}$, which does not generate loss of braking efficiency due to fading effect. The recovering time of the system up to the initial temperature (about $40^{\circ} \mathrm{C}$ ) measured after the vehicle has stopped was from 10 to 20 seconds. To avoid reading error due to rapid recovery of the system, the temperature measurements were performed immediately after vehicle has stopped.

\subsection{Results obtained from race test}

Figure 9 shows the competition circuit where the tests were carried out. The numbers indicate the track sections where the driver was acting on the brake pedal. 


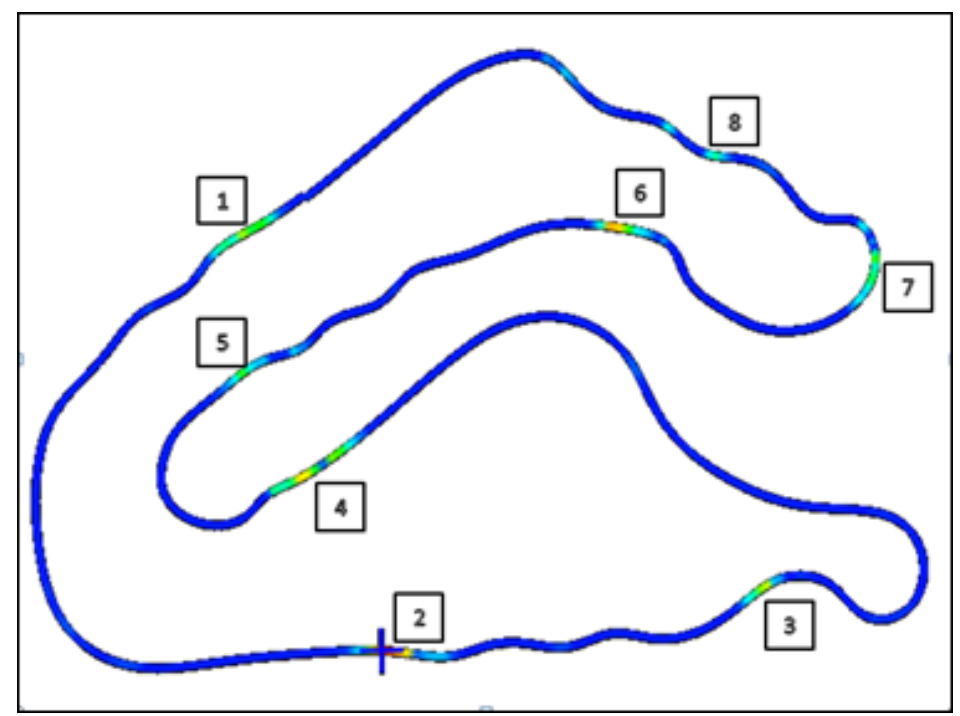

Figure 9. Braking points during the test

Several laps were completed by the driver. The results of one of than are presented below.

In the figure 10 the curve highlighted in red represents the pressure inside the front brake line and the blue curve represents the pressure inside the rear line of the brake circuit. In this lap, initially the brake bias was set of $65-35$, which means $65 \%$ braking force to the front wheels and $35 \%$ to the rear axle.

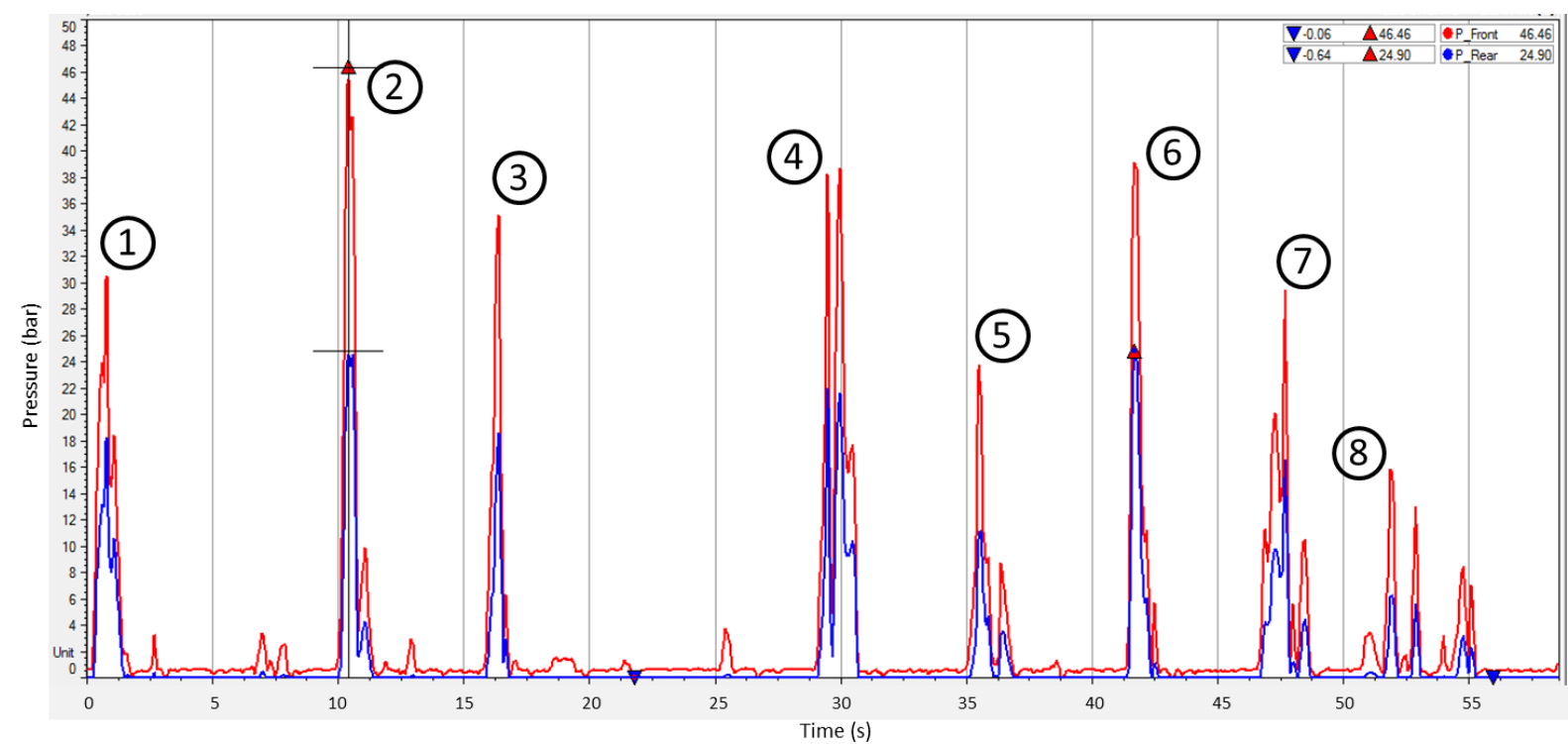

Figure 10. Pressure inside the front (red line) and rear (blue line) brake circuits

The values of front and rear line pressures obtained during tests were employed to verify the setting of brake bias, which was determined by the equation (13). Table 5 shows the results for each braking point presented in Figures 10 and 11. 
Table 5. Front and rear brake pressure

\begin{tabular}{cccccc}
\hline $\begin{array}{c}\text { Track Section } \\
\text { (see Fig. 9) }\end{array}$ & $\begin{array}{c}\text { Total Pressure } \\
(\mathrm{MPa})\end{array}$ & $\begin{array}{c}\text { Front Pressure } \\
(\mathrm{MPa})\end{array}$ & $\begin{array}{c}\text { Rear Pressure } \\
(\mathrm{MPa})\end{array}$ & \% Front & $\%$ Rear \\
\hline 1 & 4.87 & 3.05 & 1.82 & $63 \%$ & $37 \%$ \\
2 & 7.13 & 4.64 & 2.49 & $65 \%$ & $35 \%$ \\
3 & 5.38 & 3.51 & 1.87 & $65 \%$ & $35 \%$ \\
4 & 6.04 & 3.84 & 2.20 & $64 \%$ & $36 \%$ \\
5 & 3.47 & 2.34 & 1.13 & $67 \%$ & $33 \%$ \\
6 & 6.38 & 3.89 & 2.49 & $61 \%$ & $39 \%$ \\
7 & 4.56 & 2.93 & 1.63 & $64 \%$ & $36 \%$ \\
8 & 2.25 & 1.60 & 0.65 & $71 \%$ & $29 \%$ \\
\hline
\end{tabular}

Figure 11 shows the total brake pressure (obtained by adding the front and rear pressures), the vehicle longitudinal velocity and the longitudinal acceleration of the vehicle. The numbers correspond to the track section where the driver was acting on the brake pedal (see Figure 9).

The vehicle reached its maximum lap velocity of $74.6 \mathrm{~km} / \mathrm{h}$ in track section number 2 and in track section number 6 its maximum longitudinal acceleration of $1.22 \mathrm{~g}$.

When the car was in track section number 2, the pressure of brake circuit reached its peak value of $7.13 \mathrm{MPa}$ (71.3 bar). Exactly when the brake pressure achieved that peak, the longitudinal acceleration was equal to $1.06 \mathrm{~g}$ and immediately arose to $1.21 \mathrm{~g}$.

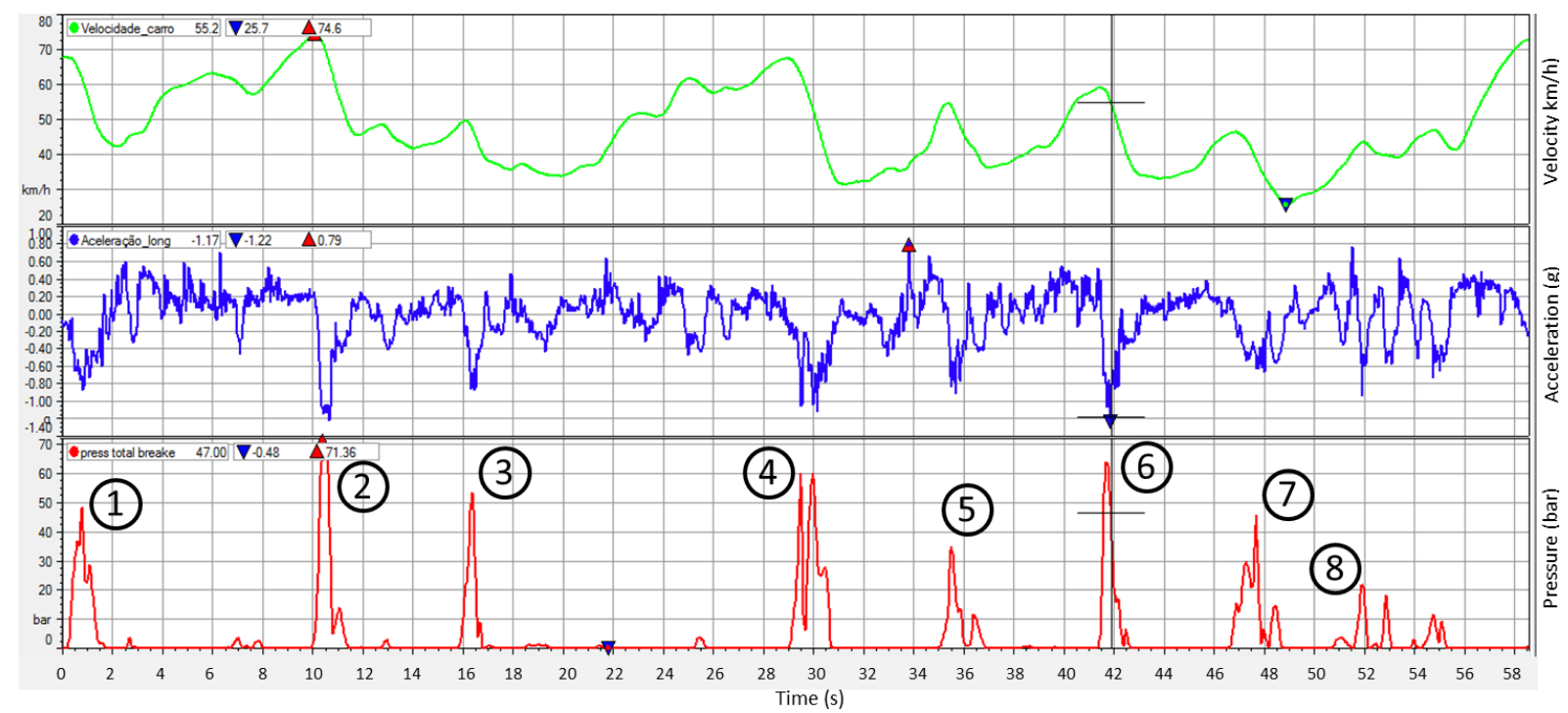

Figure 11. Vehicle Speed, Longitudinal Acceleration and Total Pressure inside the brake circuits

Table 6 shows the values of velocity, longitudinal and lateral acceleration of the vehicle at the exact instant when the brake pressure achieved the peak in each track section shown in Figure 9. Note that the peak of longitudinal acceleration did not occur at the exact moment when the brake pressure achieved its maximum value, what can be observed in Figure 11. 
Table 6. Vehicle Velocity, Longitudinal and Lateral Acceleration

\begin{tabular}{cccc}
\hline $\begin{array}{c}\text { Track Section } \\
\text { (see Fig. 9) }\end{array}$ & $\begin{array}{c}\text { Lateral } \\
\text { Acceleration }(\mathrm{g})\end{array}$ & $\begin{array}{c}\text { Longitudinal } \\
\text { Acceleration }(\mathrm{g})\end{array}$ & Velocity $(\mathrm{km} / \mathrm{h})$ \\
\hline 1 & 0.56 & 0.77 & 62.1 \\
2 & 0.70 & 1.06 & 72.5 \\
3 & 0.74 & 0.78 & 47.4 \\
4 & 0.01 & 0.85 & 63.6 \\
5 & 1.06 & 0.71 & 54.2 \\
6 & 0.42 & 0.77 & 58.6 \\
7 & -0.64 & 0.54 & 38.8 \\
8 & 1.14 & 0.82 & 43.8 \\
\hline
\end{tabular}

\section{CONCLUSION AND COMENTS}

In this paper, a brake system performance of a formula type vehicle was evaluated by both a mathematical model and an experimental test. The model was useful to analyze the braking forces distribution between the front and rear axles and to determine the suitable brake bias ratio for the vehicle to achieve the optimum brake forces balance. Moreover, the range of brake bias is good for the vehicle to reach the optimum braking performance with different drivers who will drive the car during competition.

The results obtained in the model evaluation test show that the mathematical model is suitable for brake system performance prediction. The maximum difference between the results of the model and the results of the tests is lower than $13 \%$. Moreover, while braking only in straight line, the maximum vehicle longitudinal deceleration was equal to $1.48 \mathrm{~g}$.

Finally, the tests in competition circuit show that the brake bias ratio is suitable under competition conditions. When braking in a turn, the vehicle achieves simultaneously longitudinal deceleration of $1.06 \mathrm{~g}$ and lateral acceleration of 0.7 .

The future work will concentrate on simulation and experiments considering the aerodynamic drag and downforce effects during braking.

\section{ACKNOWLEDGEMENTS}

The authors would like to thank all the past and present members of the Maua Racing Team of Maua Institute of Technology and the advisor Willian Kurilov de Moraes.

\section{REFERENCES}

[1] SAE, Formula SAE 2017-18 Rules, Available at http://www.fsaeonline.com/content/2017. Accessed on march, 2018.

[2] FSG, Formula Student Germany 2018 Rules, Available at https://www.formulastudent.de/. Accessed on march, 2018.

[3] MILLIKEN, W. F.; MILLIKEN, D. L. Race car vehicle dynamics. Warrendale: SAE Inc, 1995.

[4] CANALE, A. C. Automotive: dynamics and performance. Sao Paulo: Érica, 1989. In portuguese. 
[5] GILLESPIE, T. D. Fundamentals of Vehicle Dynamics. 3th Ed. Warrendale: SAE Inc, 1994.

[6] LIMPERT, R. Brake design and safety. 2 ed. Warrendale, US: Society of Automotive Engineers. Elsevier Ltd., 1999.

[7] BREUER, B.; BILL, K.H., Brake Technology Handbook. Warrendale: SAE Inc, 2008.

[8] HEFFERNAN, M. E. Analyzing and Simulating Brake Rotor Temperatures: A Technique Applied to a Formula SAE Vehicle, SAE Technical Paper 2006-01-1974, Detroit MI, 2006.

[9] SCHOMMER, A., HASELEIN, B. Z., FARIAS, L. T., SOLIMAN, P., OLIVEIRA, L. C., Design of a Brake Caliper using Topology Optimization Integrated with Direct Metal Laser Sintering, SAE Technical Paper 2015-36-0539, Detroit MI, 2015.

[10] WALLENTOWITZ, H. Lecture Longitudinal Dynamics of Vehicle. 4 th Ed. Aahen: ika-RWTH, 2004.

[11] PACEJKA, H. B. Tire and Vehicle Dynamics. 2nd Ed. Warrendale: SAE Inc, 2006.

\section{Appendix}

VEHICLE PARAMETERS EMPLOYED IN SIMULATIONS AND EXPERIMENTAL TESTS

\begin{tabular}{cc}
\hline Vehicle Parameter & Value \\
\hline $\begin{array}{c}\text { Vehicle mass (without } \\
\text { driver) }\end{array}$ & $275 \mathrm{~kg}$ \\
\hline Gravitational acceleration & $9.81 \mathrm{~m} / \mathrm{s}^{2}$ \\
\hline $\begin{array}{c}\text { Distance between front axle } \\
\text { and gravitational center }\end{array}$ & $\begin{array}{c}\text { From } 781 \text { to } \\
800 \mathrm{~mm}\end{array}$ \\
\hline Wheel base length & $1578 \mathrm{~mm}$ \\
\hline $\begin{array}{c}\text { Gravitational center height } \\
\text { Tire/road adhesion } \\
\text { coefficient }\end{array}$ & From 330 to \\
& From $055 \mathrm{~mm}$ \\
\hline $\begin{array}{c}\text { Driver mass: } \\
\text { First CG position } \\
\text { (simulation) }\end{array}$ & $60 \mathrm{~kg}$ \\
Second CG position \\
(simulation) \\
$\begin{array}{c}\text { Model evaluation test } \\
\text { Competition circuit test }\end{array}$ \\
\hline
\end{tabular}

\begin{tabular}{|c|c|}
\hline Vehicle Parameter & Value \\
\hline Pedal force $(\max )$ & $450 \mathrm{~N}$ \\
\hline $\begin{array}{c}\text { Master cylinder } \\
\text { diameter (front and rear) }\end{array}$ & $19.35 \mathrm{~mm}$ \\
\hline Pedal ratio $\left(\ell_{1} / \ell_{2}\right)$ & 5.75 \\
\hline Pushout pressure & $5.10^{4} \mathrm{~Pa}$ \\
\hline Brake bias ratio & $\begin{array}{c}\text { From } 50 \% \text { to } \\
80 \%\end{array}$ \\
\hline $\begin{array}{l}\text { Effective radius disc } \\
\text { brake (front and rear) }\end{array}$ & $85 \mathrm{~mm}$ \\
\hline $\begin{array}{l}\text { Caliper piston diameter } \\
\text { (dual piston caliper- } \\
\text { front and rear) }\end{array}$ & $25 \mathrm{~mm}$ \\
\hline Brake factor $\left(2 \mu_{p a d}\right)$ & 0.64 \\
\hline Tire rolling radius & $240 \mathrm{~mm}$ \\
\hline $\begin{array}{l}\text { Wheel cylinder } \\
\text { efficiency }\end{array}$ & 0.95 \\
\hline
\end{tabular}


CIRCUITS PRESSURE, VEHICLE VELOCITY AND ACCELERATION COLLECTED DURING MODEL EVALUATION TEST

The time unit employed in the graphs below is Minute : Second.

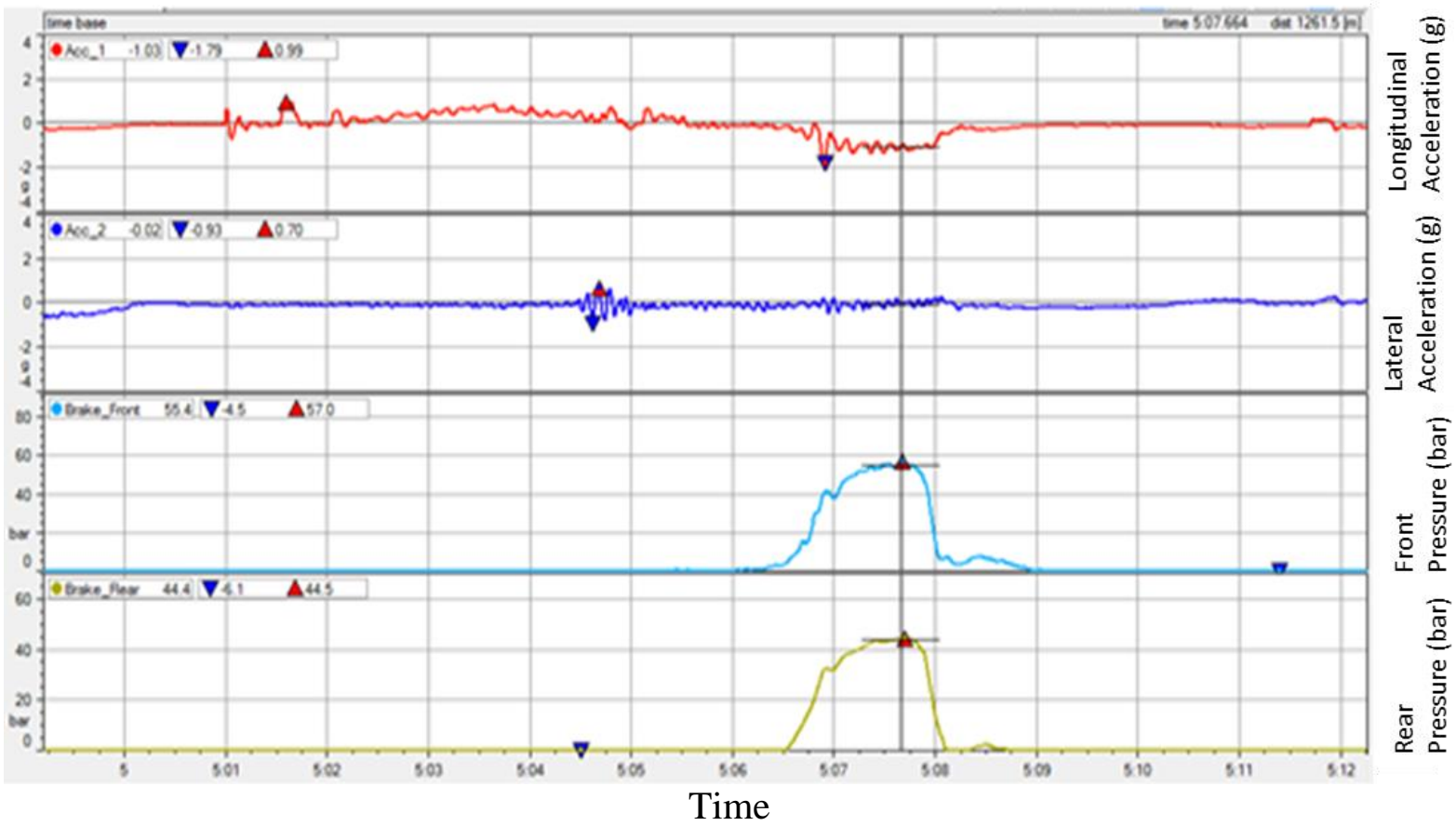

Graph A1. Circuits pressure, lateral and longitudinal vehicle acceleration (Test 1 - Table 3)

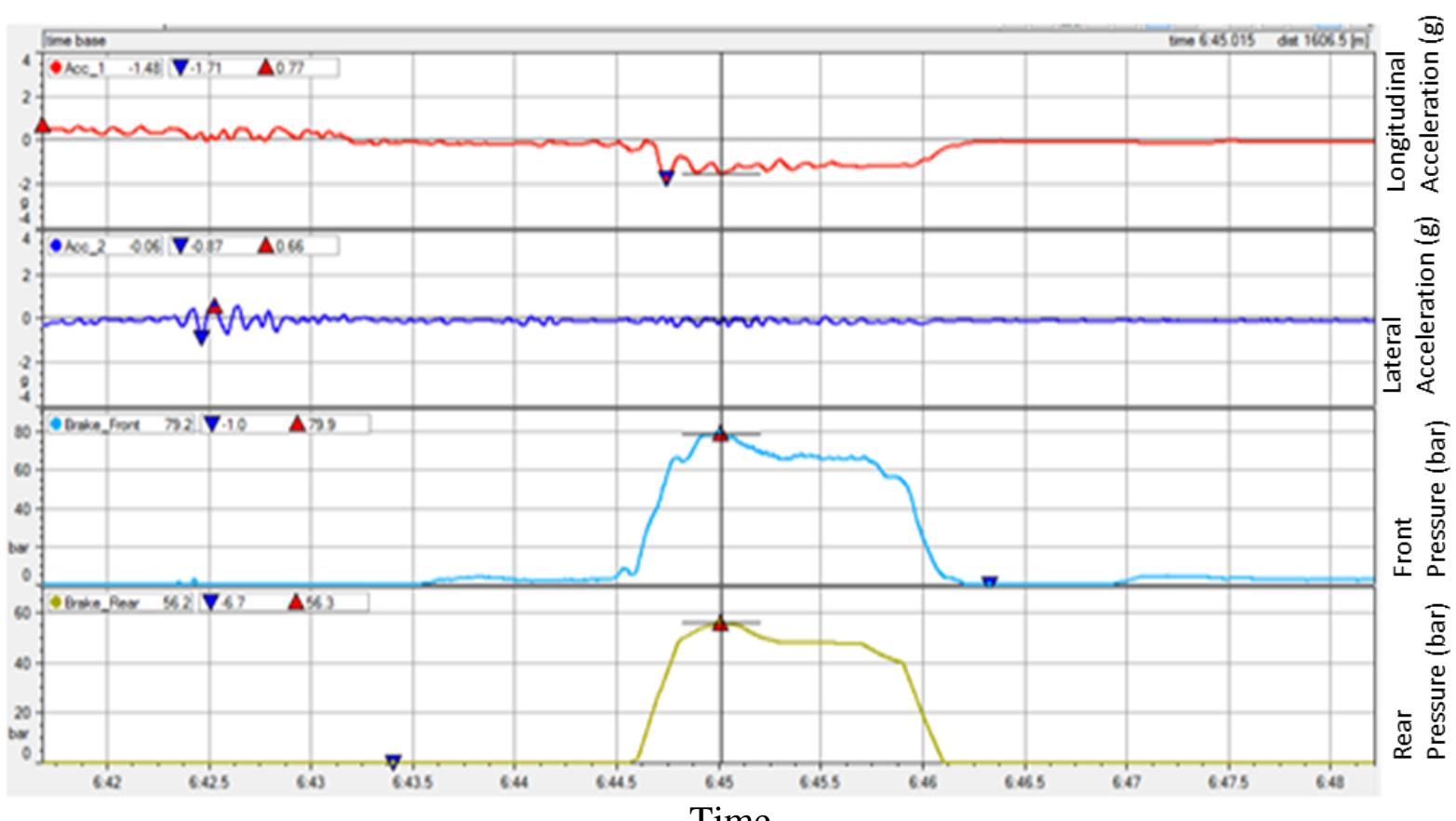

Graph A2. Circuits pressure, lateral and longitudinal vehicle acceleration (Test 2 - Table 3) 


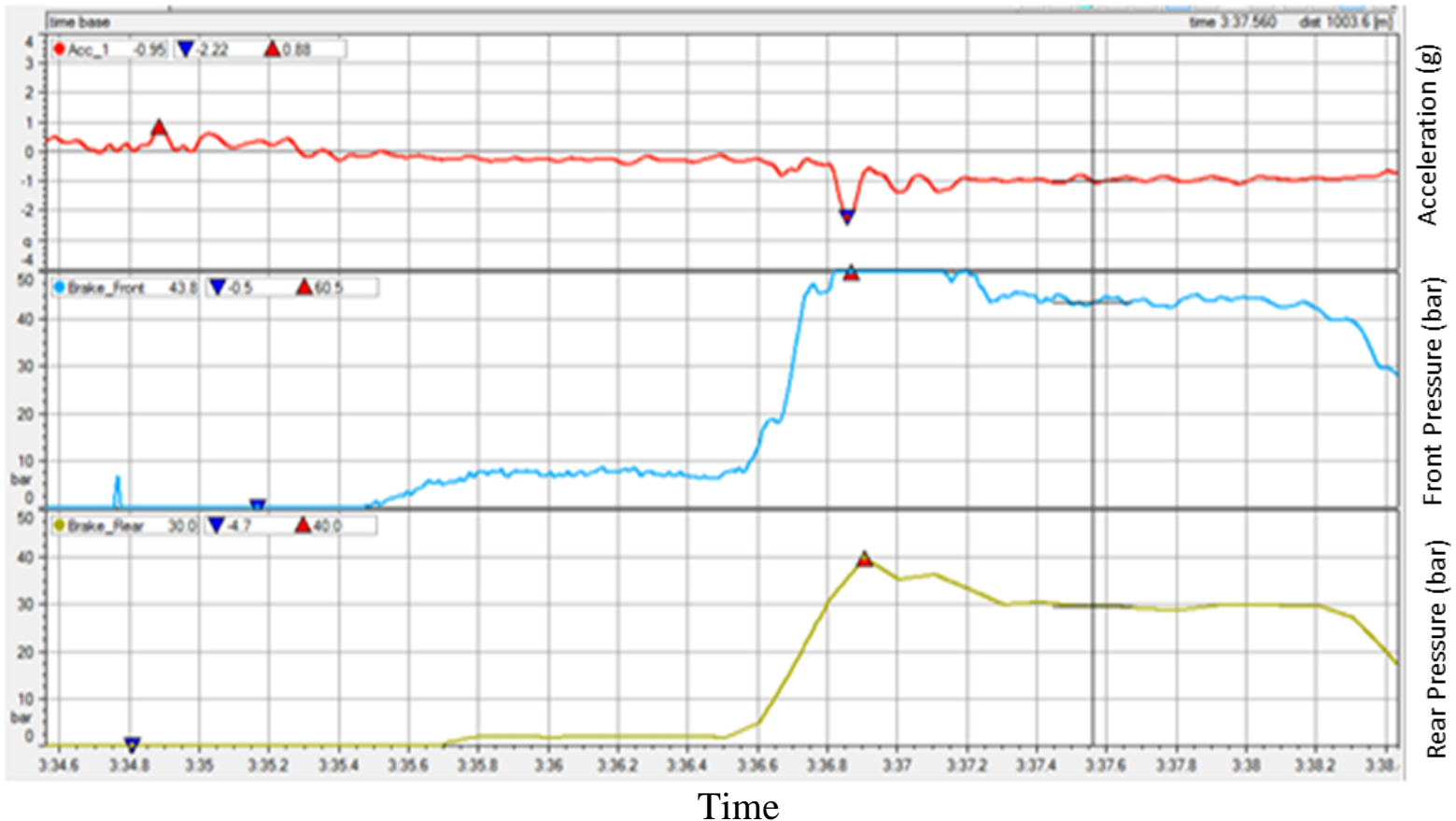

Graph A3. Circuits pressure and longitudinal vehicle acceleration (Test 3 - Table 3)

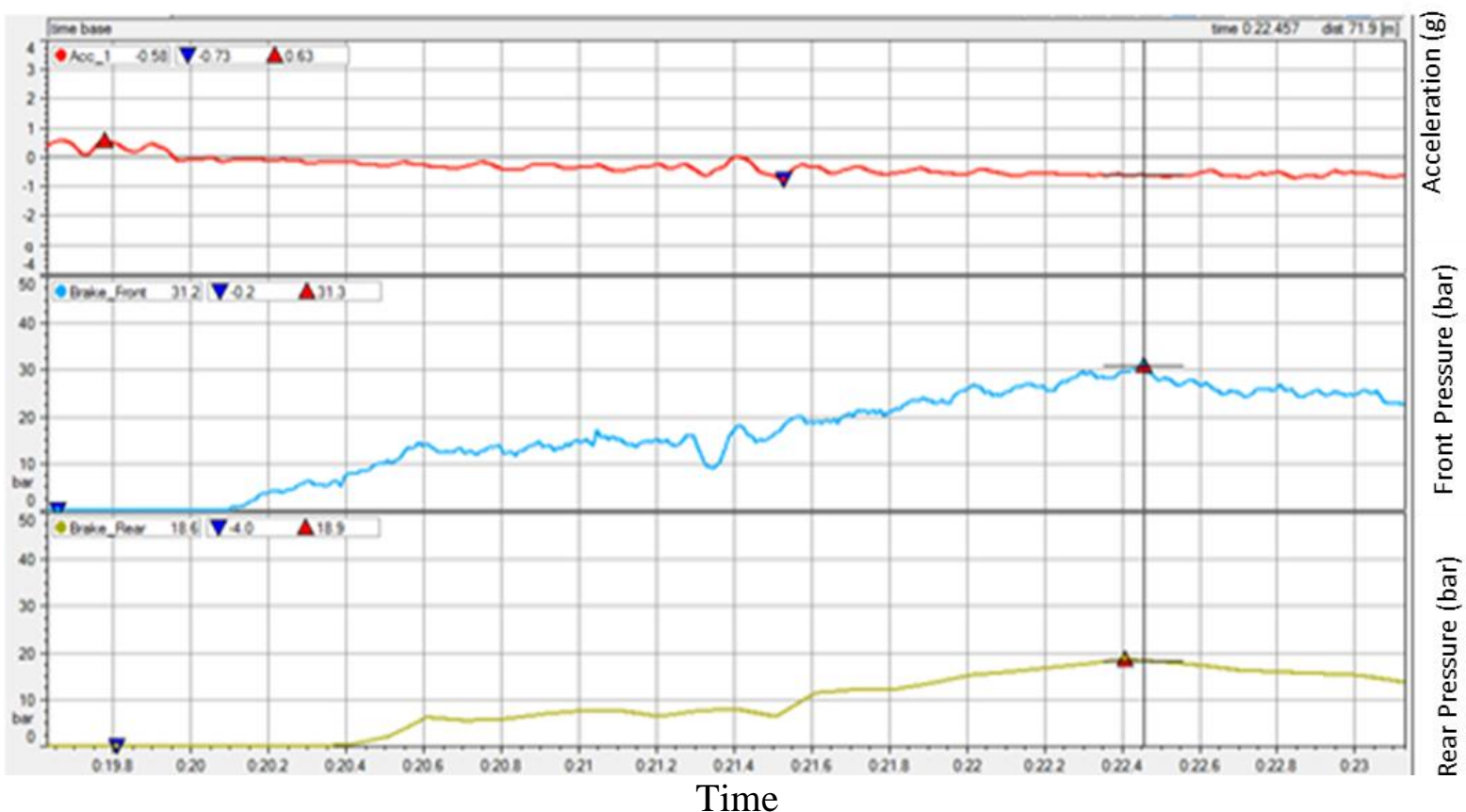

Graph A4. Circuits pressure and longitudinal vehicle acceleration (Test 4 - Table 3) 


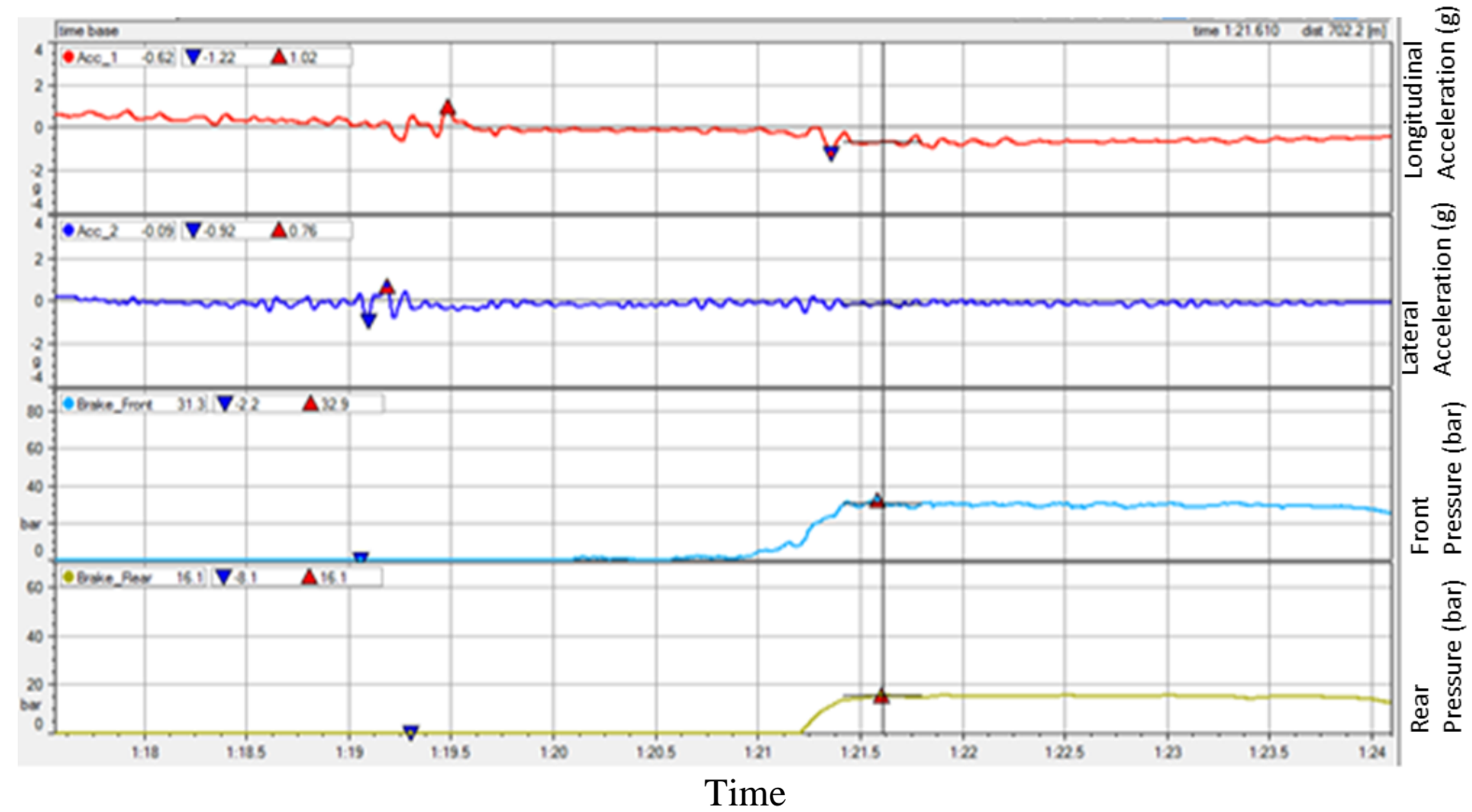

Graph A5. Circuits pressure, lateral and longitudinal vehicle acceleration (Test 5 - Table 3)

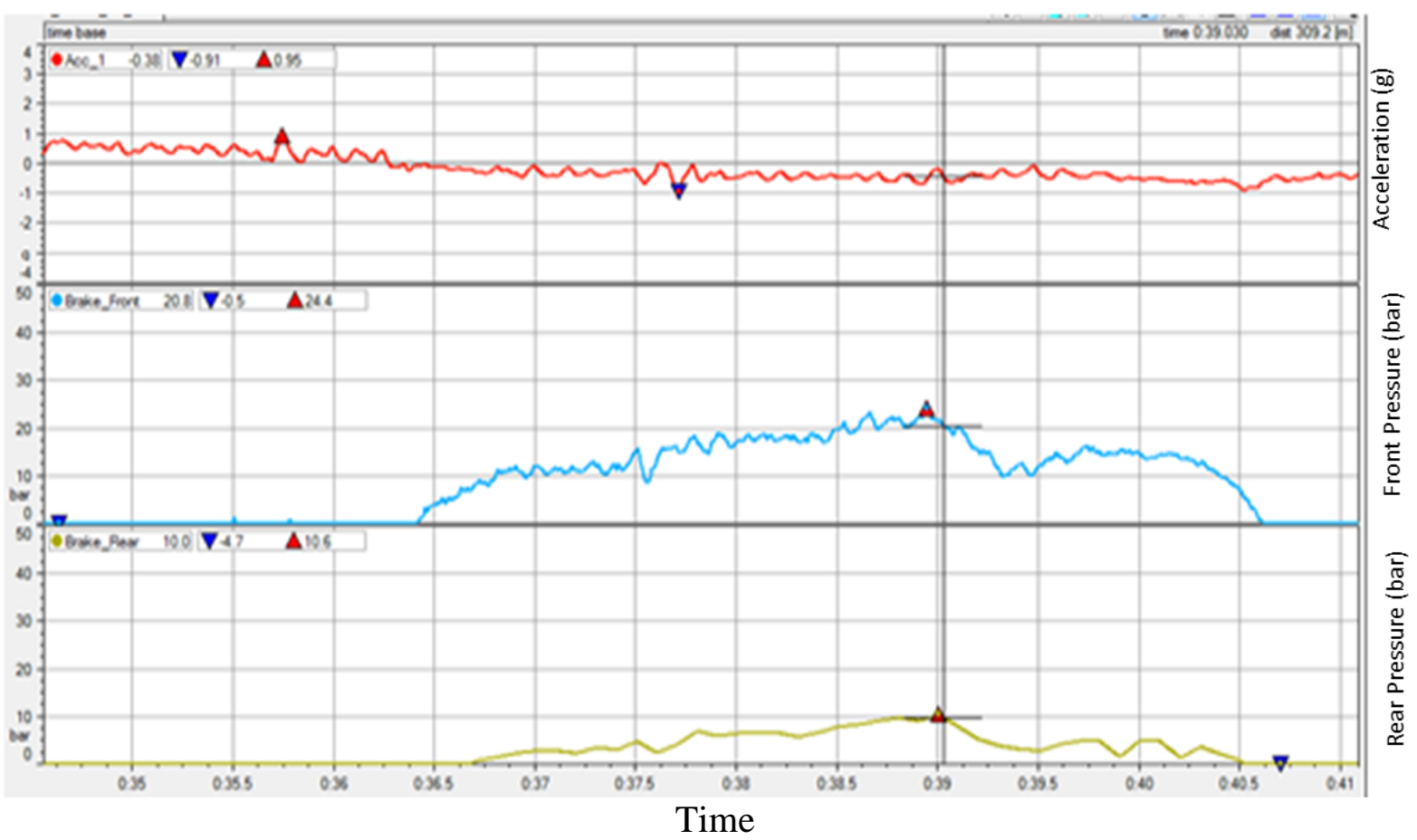

Graph A6. Circuits pressure and longitudinal vehicle acceleration (Test 6 - Table 3) 